\title{
Comparison of salt content in breads offered in bakeries in South Khorasan province in 2014-2018
}

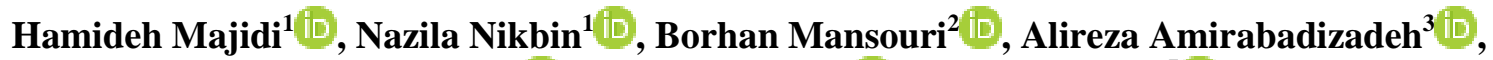 \\ Kobra Naseri $^{2}$ (D), Zohreh Kamiar ${ }^{4}$, Ali Naghizadeh ${ }^{5}$ \\ ${ }^{1}$ Student Research Committee, Birjand University of Medical Sciences, Birjand, Iran \\ ${ }^{2}$ Medical Toxicology and Drug Abuse Research Center (MTDRC), Birjand University of Medical Sciences, Birjand, Iran \\ ${ }^{3}$.Cardiovascular Diseases Research Center, Birjand University of Medical Sciences, Birjand, Iran \\ ${ }_{5}^{4}$ Food and Drug Organisation, Birjand University of Medical Sciences, Birjand, Iran \\ ${ }^{5}$ Corresponding author; Medical Toxicology and Drug Abuse Research Center (MTDRC), Birjand University of Medical Sciences, \\ Birjand, Iran; Tel: +985632381665 Fax: +985632440117Ｅ-mail: Al.naghizadeh@yahoo.com
}

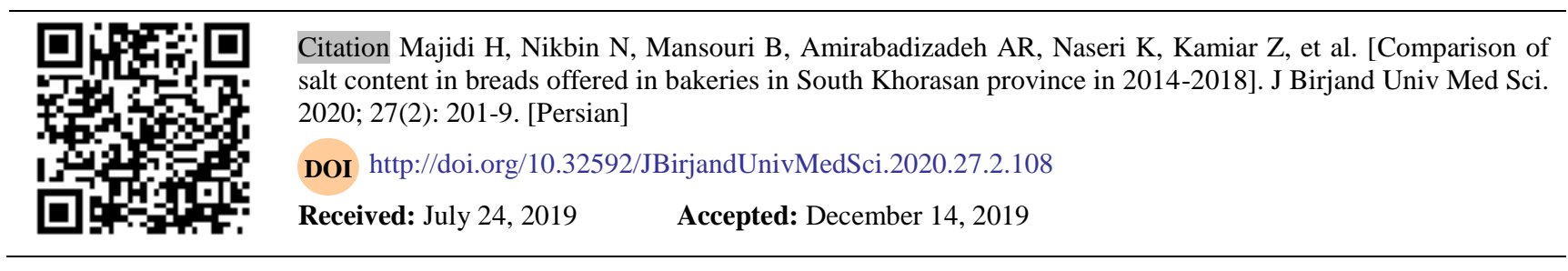

\begin{abstract}
Background and Aim: Adding salt to foods including bread along with improving its taste can cause problems such as high blood pressure; therefore, considering the importance of the presence of salt in bread, the purpose of this study was to investigate the amount of bread salt in bakeries in South Khorasan province in 2014-2018.
\end{abstract}

Materials and Methods: This descriptive-analytical and retrospective study was performed by random sampling method on bakeries in South Khorasan province in the period of 2014-2018. The measurement of the salt level was done according to the standards of the Iranian Institute of Standards and Industrial Research. The data were analyzed by using variance analysis tests and Tukey's post-hoc test.

Results: 2577 loaves of bread were sent to the food laboratory of South Khorasan province during the years 2014-2018, which is the total average amount of salt In Lavash bread, it was equal to $1.63 \pm 0.57 \mathrm{~g}$, Taftoon was $1.51 \pm 0.53 \mathrm{~g}$, and in Sangag bread, it was $1.42 \pm 0.56 \mathrm{~g}$. The mean of salt levels in years had significantly various $(\mathrm{p}<0.001)$.

Conclusion: Our result showed that the amount of salt in bread was highest in 2016. It seems to be due to the lack of awareness of bakers about changing the standard of salt in that year. In this regard, the adoption of preventive and regulatory programs by the Food and Drug Administration can be a guide.

Key Words: Bakery; Bread; Salt; South Khorasan 


\title{
مقايسه ميزان ذمك در نانهاى عرضه شده در نانوايىهاى استان خراسان جنوبى در سالهاى
}

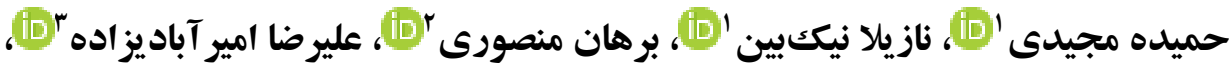

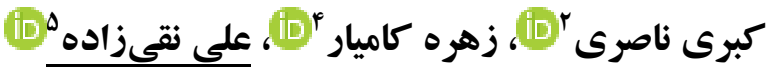

جكيده

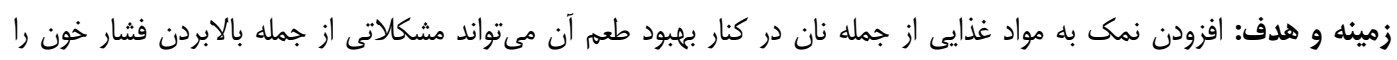

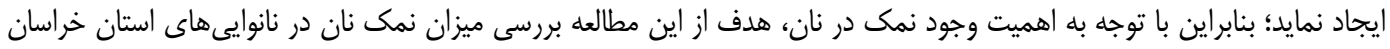

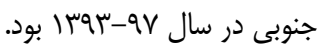

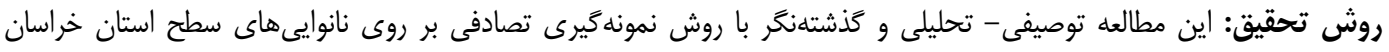

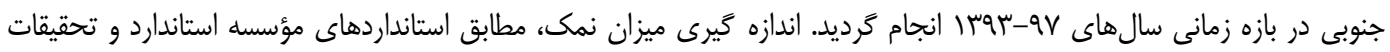

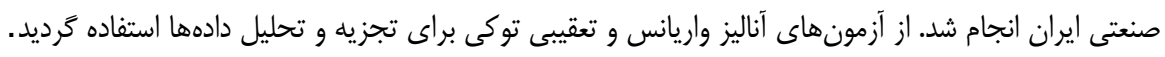

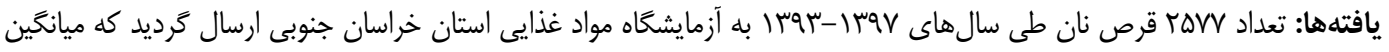

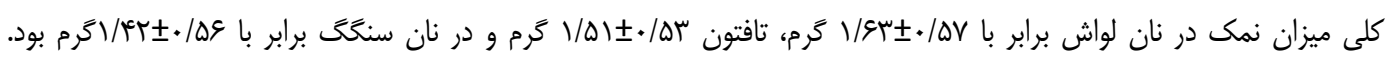

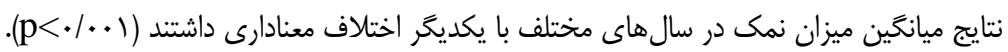

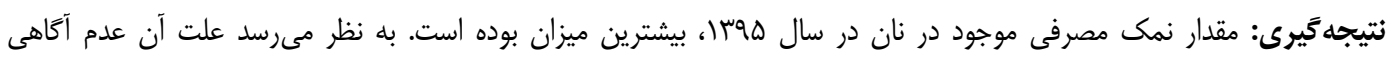

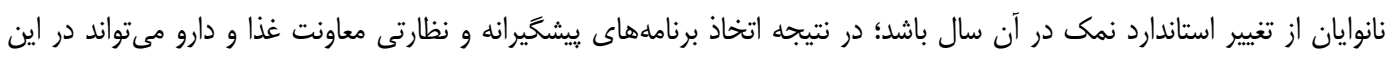
زمينه رهگشا باشد.

وازههاى كليدى: نانوايى؛ نان؛ نمك؛ خراسان جنوبى

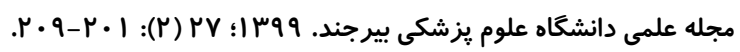

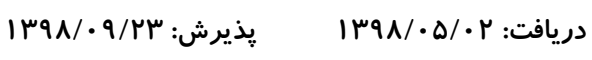


استانهاى كشور درباره وضعيت نان در نانوايىها صورت مقدمه

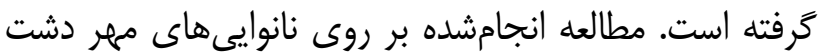

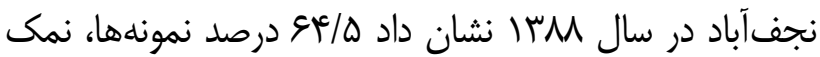
بيش از حد استاندارد داشتند و ميزان رعايت استاندارد استفاده

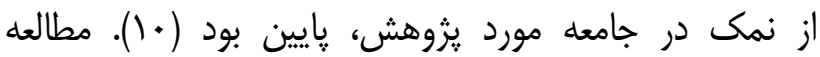

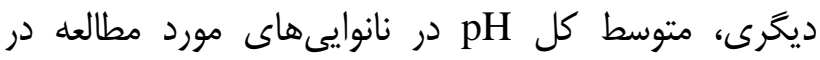

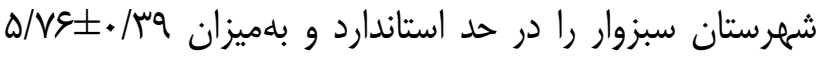

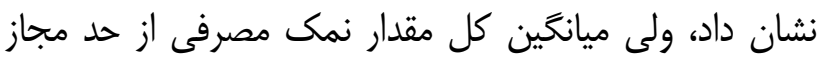

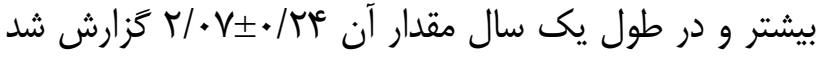
تص (V)

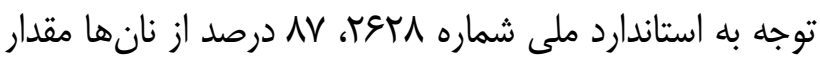

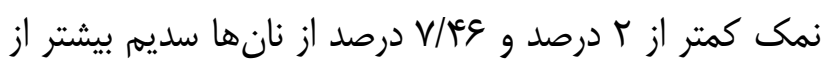

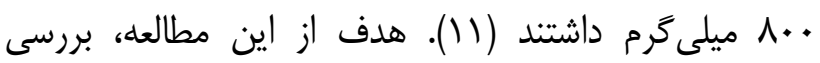

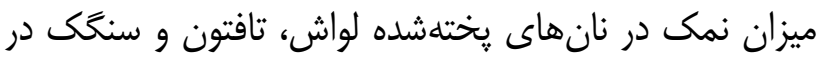

\section{روش تحقيق}

در اين مطالعه توصيفى - تحليلى و كذشتنهنگ، كليه

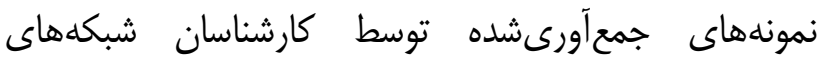

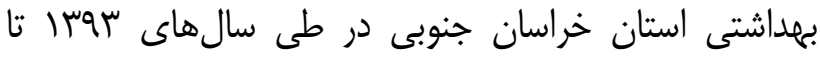

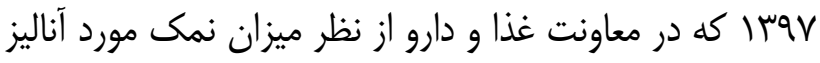

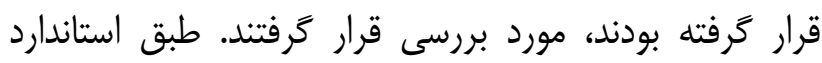

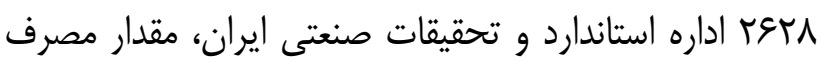

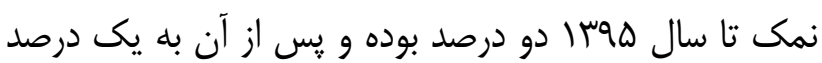
تغيير كرده است. تمن سال نمونه گيرى توسط كارشناسان شبكهها در هر ماه به اين

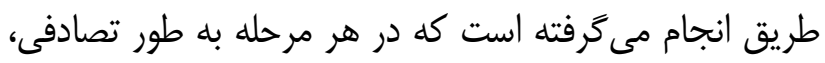

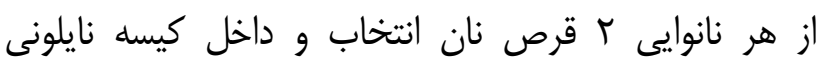

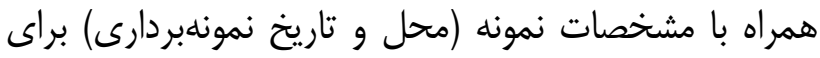

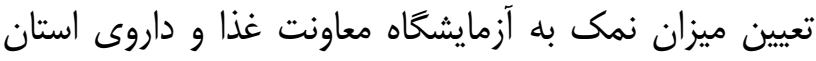

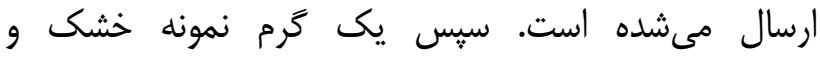

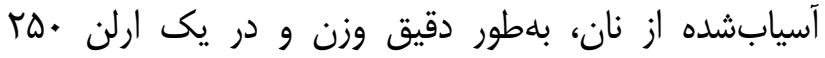

نان بلهنوان مهمترين منبع غذايى مردم، اهميت ويزهاى

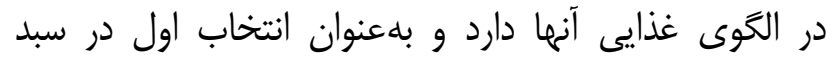

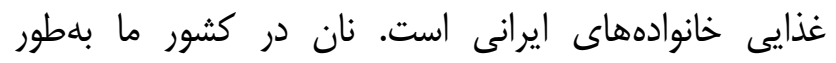

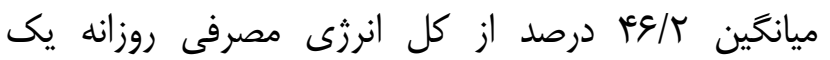

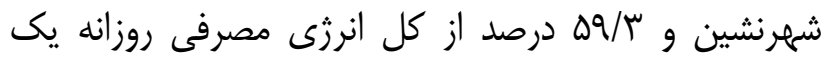

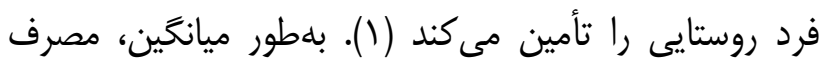

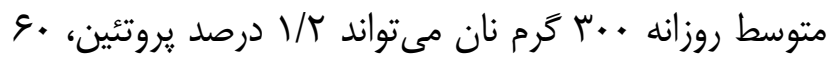

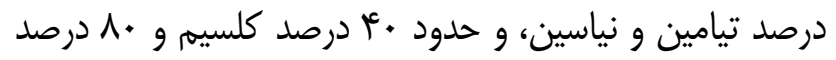

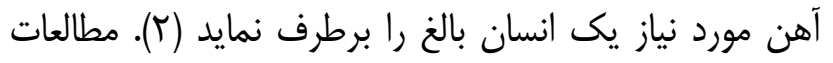
نشان مىدهد در ايرلند

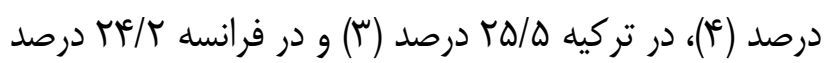
(ه) كل نمك مصرفى از نان حاصل مى شود.

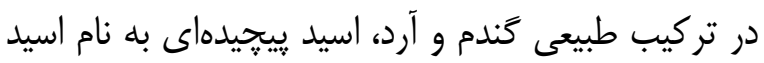
فيتيك وجود دارد كه با مواد معدنى مثل آهن و كلسيهم تركيب

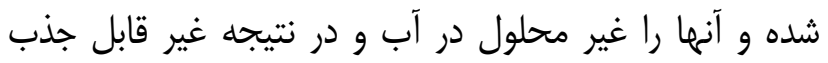

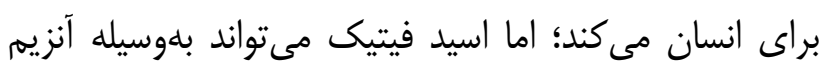

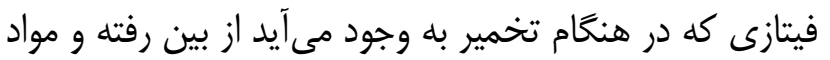

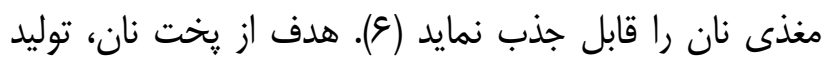
محصولى با ظاهر و حجم مناسب و قابليت هضم زياد است آنا

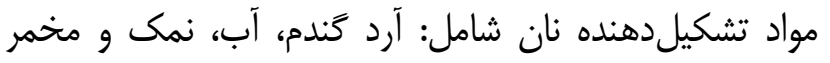

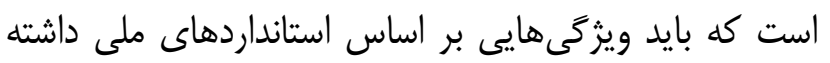

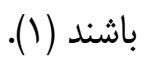
نمك بلهنوان منبع تأمين كننده يونهاى ضرورى بدن است كه در تنظيه درجه حرارت بلن، هموستاز، تعيين حجم بهم

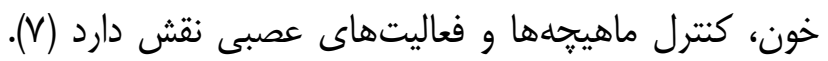
مصرف بيش از حد نمك سبب افزايش فشار خون، سكته

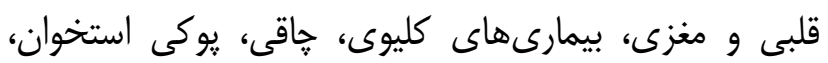

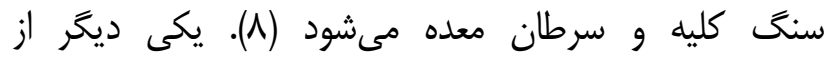
ييامدهاى مصرف بيش از حد نمك، تجمع كلسترول در

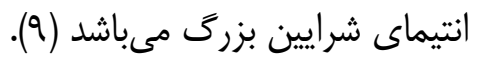
با توجه به اهميت نمك در نان، مطالعاتى در برخى از 


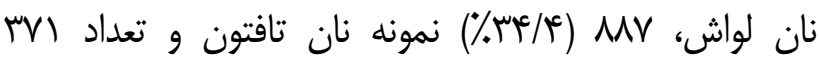
(F/\%)

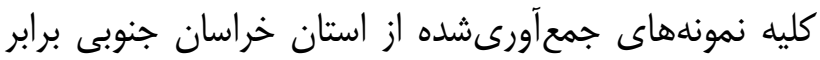

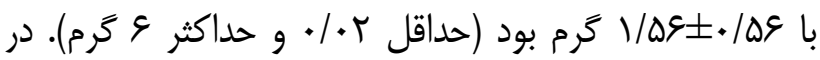

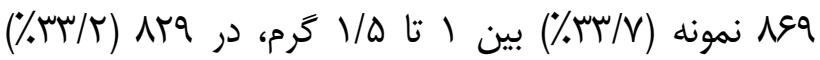

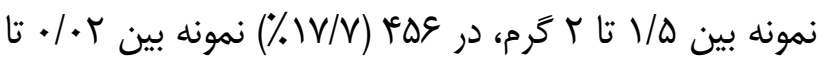

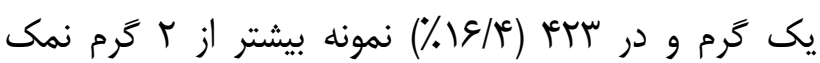

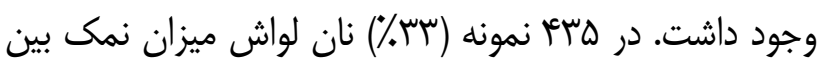

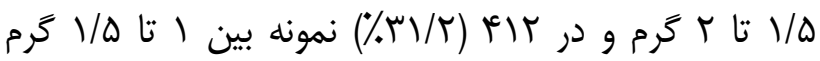

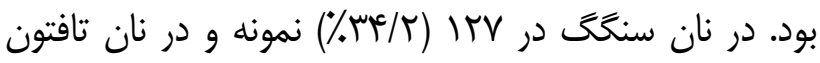

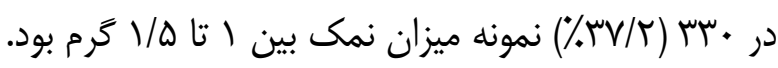

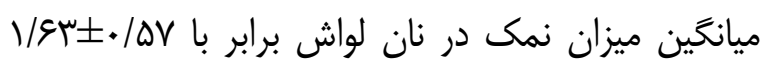

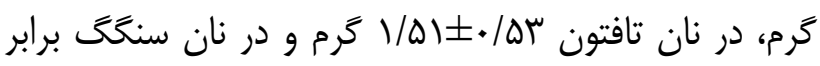

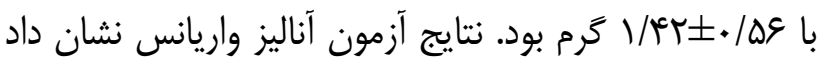

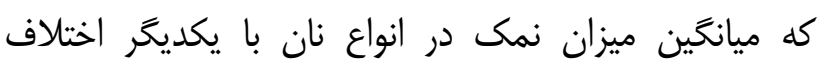

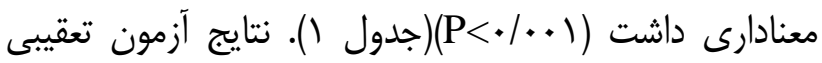

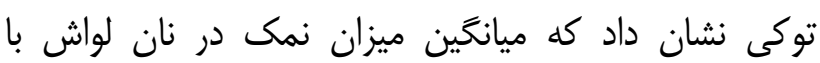
اختلاف معنادارى بيشتر از نان سنكگ و و تافتون بود؛ همجينين

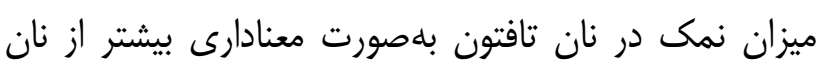

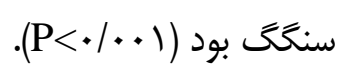

ميانكَين ميزان نمك در نمونههاى جمعآورى آشده در سال هو

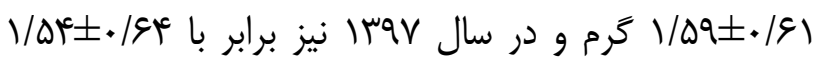

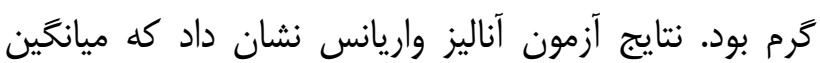

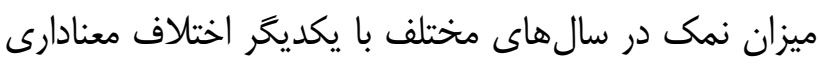

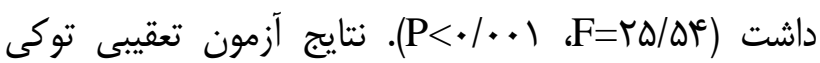

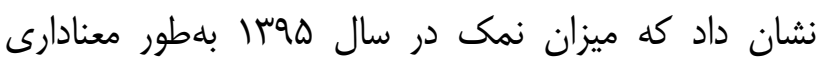

ميلىليترى ريخته مىشده و به آن •ا ميلىليتر از محلول

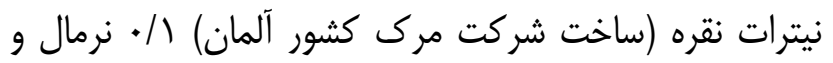
سبِ •إميلىليتر اسيد نيتريك غليظ افزوده مى شده است؛ سبِ اين مخلوط حرارت داده مىشده است تا بجوشد. در

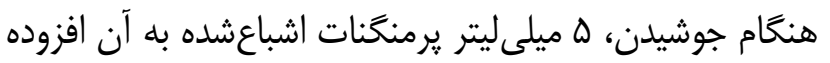

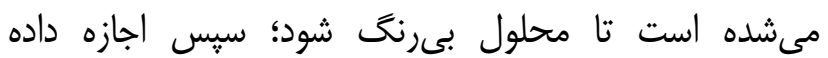

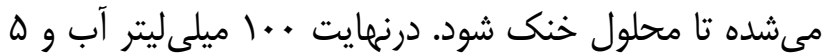

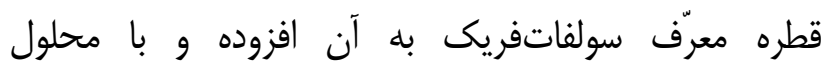

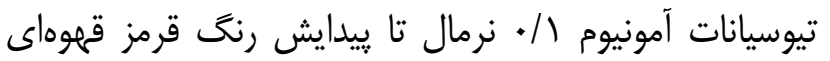

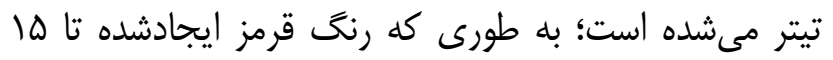

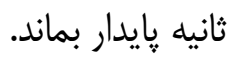
يك ميلى ليتر محلول نيترات نقره / / نرمال معادل است

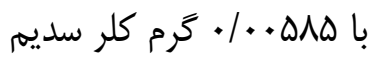

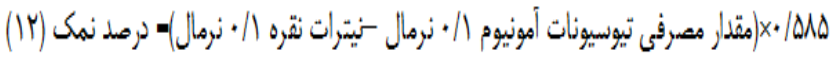
در مطالعه حاضر به منظور، تجزيه و تحليل دادهها با

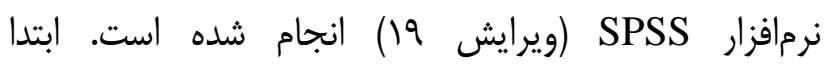
شاخصهاى توصيفى شامل: ميانكين، انحراف معيار و فراوانى كزارش شد؛ سيس براى بررسى ميزان نمك در انواع نان و ودر

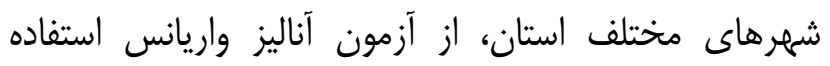

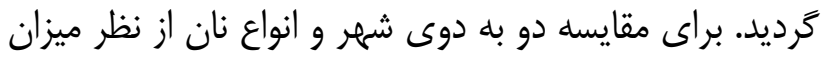

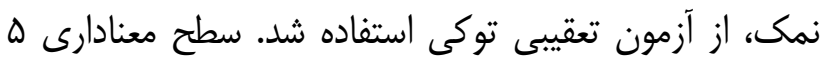
درصد در نظر كَرفته شد. اين مطالعه داراى كد اخلاق آلاق به شماره Ir.bums.REC.1398.79 مىباشد.

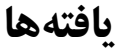

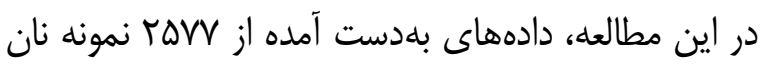
مربوط به تمامى شهرستانهاى استان خراسان جنوبى، تجزيه

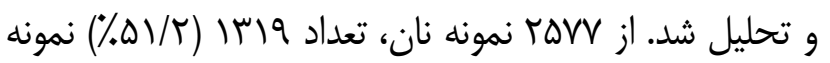


جدول ا - مقايسه ميانكين ميزان نمك بر حسب نوع نان به تفكيك شهرستان هاى استان خراسان جنوبى

\begin{tabular}{|c|c|c|c|c|c|}
\hline نتيجه آزمون تعقيبى & سنكَك & 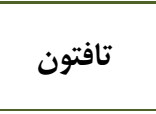 & ل ل لواش & 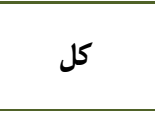 & شهرستان \\
\hline 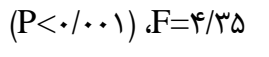 & $1 / \& \Psi \pm \cdot / \Delta V$ & $1 / A Y \pm \cdot / D g$ & $1 / \Delta T \pm \cdot(\Delta)$ & $1 / 4 \wedge \pm \cdot / D T$ & بيرجند \\
\hline$(\mathrm{P}<\cdot / \cdot .1) ، \mathrm{~F}=r / \uparrow \wedge$ & $1 / 4+1 \cdot 1 \cdot 1$ & $|/ \Lambda| \pm \cdot / \Delta \Lambda$ & $1 / \Delta S \pm \cdot / \Delta T$ & $|/ G| \pm \cdot / \Delta F$ & مناطق روستايى بيرجند \\
\hline $\mathrm{P}=\cdot / 1 \cdot\left(\mathrm{F}=\mathrm{r} / \kappa^{c}\right)$ & $1 / 9 \cdot \pm \cdot / I V$ & $1 / \Delta \wedge \pm \cdot / 4 \varphi$ & $1 / 9 \cdot \pm \cdot / 4 \mathrm{~V}$ & $1 / V q \pm \cdot / 4 V$ & بشرويه \\
\hline $\mathrm{P}=\cdot / \wedge \uparrow ، \mathrm{~F}=\cdot / / \vee$ & $1 / \uparrow^{\vee} \bigvee \pm \cdot / 9 Q$ & I/RED./GT & $1 / D 1 \pm \cdot / 9 V$ & $1 / \& 9 \pm \cdot / 90$ & خوسف \\
\hline $\mathrm{P}<\cdot / \cdot \cdot 1 ، \mathrm{~F}=1 r / q \mu$ & $1 / \wedge \pm \cdot / 4$ & $|/ \varepsilon| \pm \cdot / 4$ & $1 / \vee \wedge \pm \cdot / \& q$ & $\mid / q \wedge \pm \cdot / \kappa \wedge$ & درميان \\
\hline$(\mathrm{P}<\cdot / . .1) ، \mathrm{~F}=\Delta / 9)$ & $1 / \Delta s \pm \cdot|\Delta|$ & $1 / 98 \pm \cdot / \Delta T$ & $r / M \Lambda \pm \cdot / V \varepsilon$ & $|/ V \& \pm \cdot| 9 \mid$ & زيركوه \\
\hline $\mathrm{P}=. / \cdot q ، \mathrm{~F}=r / \wedge 9$ & $1 / F Y \pm \cdot / D F$ & 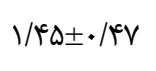 & $1 / v \cdot \pm \cdot 191$ & $|/| \pm| \pm \cdot| q \mid$ & سرايان \\
\hline $\mathrm{P}=\cdot / V \wedge ، \mathrm{~F}=\cdot / r{ }^{c}$ & $1 / \Delta \& \pm \cdot / \Phi$ & V/DTE*/א\& & $1 / A^{e} \pm \cdot / F^{e}$ & $1 / \Delta I \pm \cdot / 4 F$ & سربيشه \\
\hline$(\mathrm{P}<\cdot / \cdot \cdot 1) ، \mathrm{~F}=\Delta / q T$ & $1 / r \Delta \pm \cdot / q T$ & $1 / \Delta \Psi \pm \cdot / 9 \Delta$ & $1 / N \pm \pm \cdot / \Delta T$ & $1 / 9 \Delta \pm \cdot / \Delta \Lambda$ & فردوس \\
\hline $\mathrm{P}<\cdot / \cdot \cdot 1 ، \mathrm{~F}=1 \cdot / 4 \mathrm{~F} V$ & $1 / 1 r \pm \cdot / r \mu$ & $1 / \Delta T \pm \cdot / \& q$ & $/ / 99 \pm \cdot / 8 \wedge$ & $1 / \mathrm{V} \pm \cdot / 99$ & قاين \\
\hline $\mathrm{P}=\cdot / \cdot \wedge \mathrm{F}=r / \Delta \omega$ & $1 / \Lambda \Lambda \pm \cdot /$ & $|/ \Delta| \pm \cdot / \mu \Lambda$ & $V / \& V \pm \cdot / D F^{c}$ & $1 / \Delta V \pm \cdot / \& \Delta$ & ن مهبندان \\
\hline
\end{tabular}

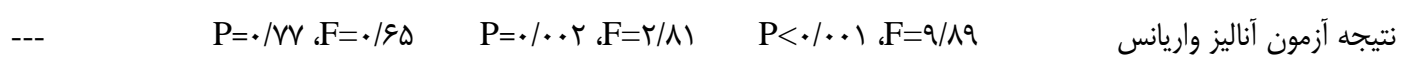

لواش نيز ميانخين نمك در بيرجند و خوسف بلطور معنادارى

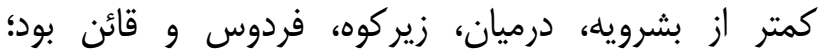

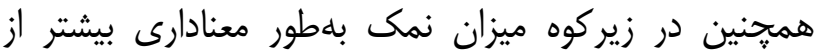
نهبندان، سرايان، سربيشه و مناطق روستايى بيرجند بود.

نتايج مطالعه حاضر نشان مىدهد كه در سالهاى مختلف

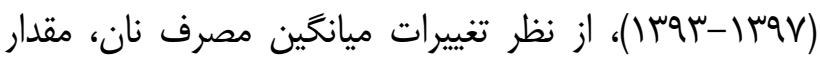

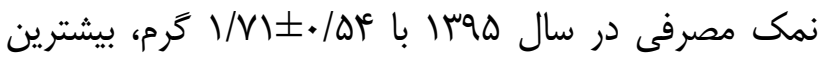

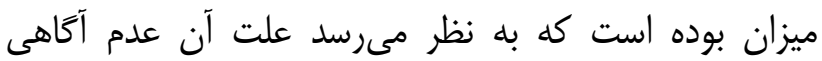

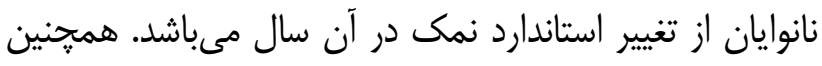
ميانخين ميزان نمك در شهرستانهاى مختلف استان نشان

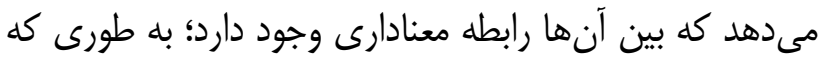

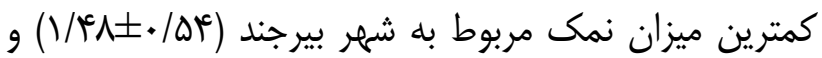

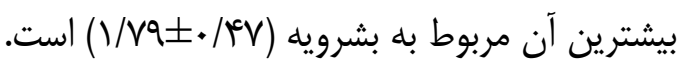

بيشتر از سالهاى سوسا، عqسו، عوسا و لوجسا بود

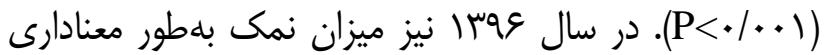

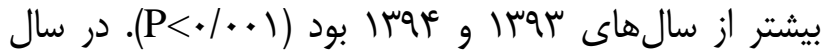
هوسا، بيشترين ميزان نمك مربوط به نانهاى لواش و

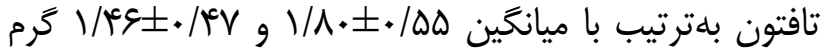
بود. در سال سوسا بيشترين ميزان نمك مربوط به به نان تافتون

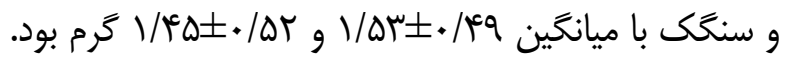
ميانكين ميزان نمك در تمامى نمونههاى جمعآورىشده

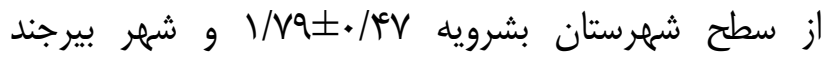

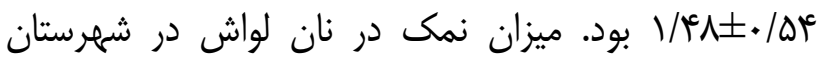
زير كوه /

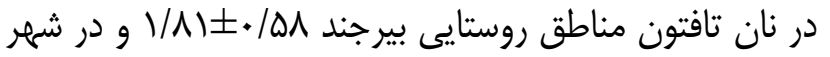

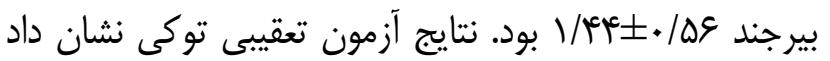
كه ميانگين نمك در نان تافتون در مناطق روستايى بيرجند

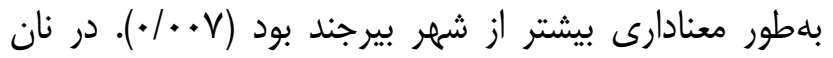


در مطالعه حاضر، أ/ع| درصد نانهاى مصرفى در

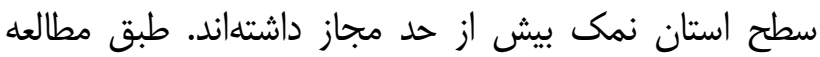

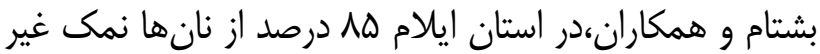

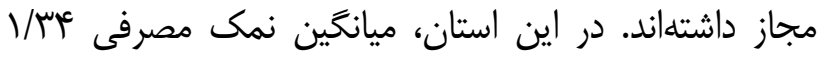

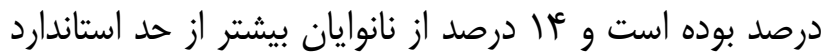
و ع/אس درصد نمك مورد نياز را كمتر از حد نرمال استفاده

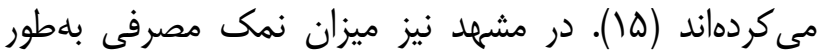

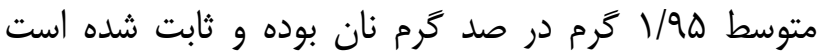

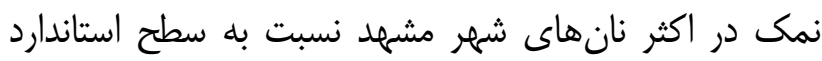

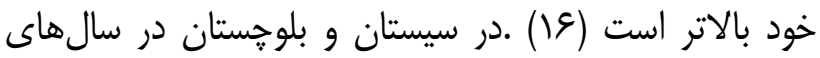

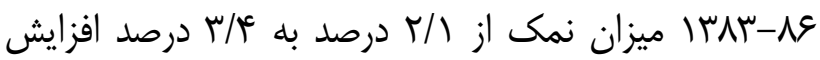

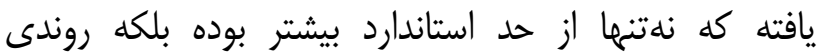

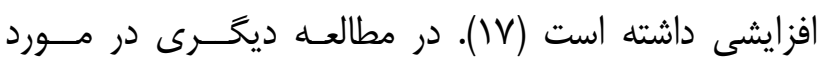

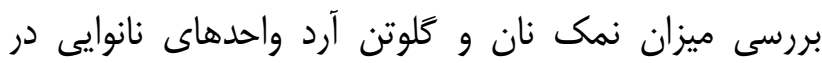

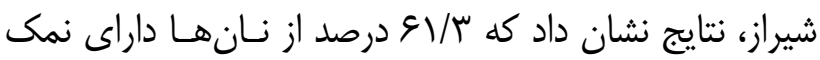
نامطلوب بودند (1). در مطالعه انجامشده توسط ملكوتيان و

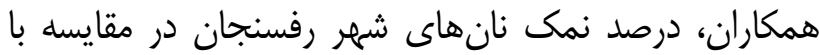

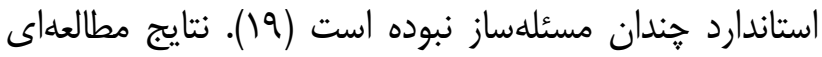
نشان داد كه انگَلستان در حال حاضر در زمينه كاهش مقدار

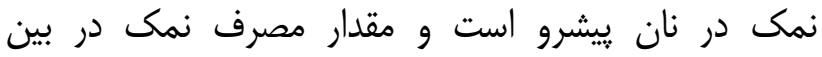

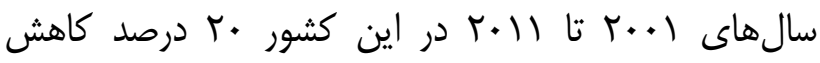

داشته است (r. (r).

با توجه به نتايج بلهدت آمده، به نظر مىرسد نانوايان

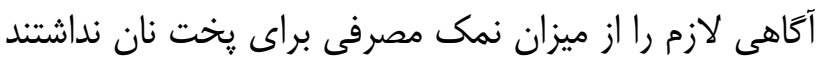

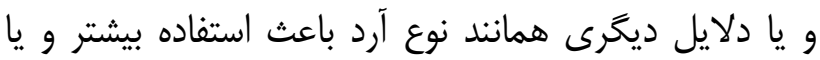

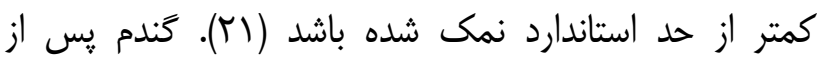

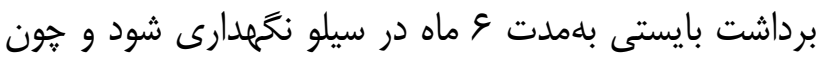

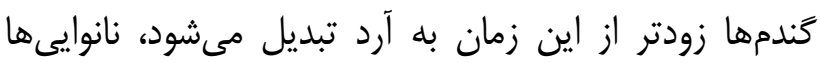

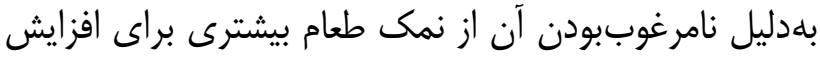

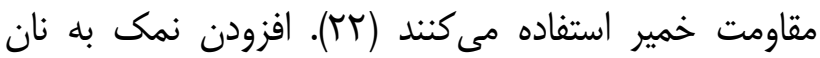

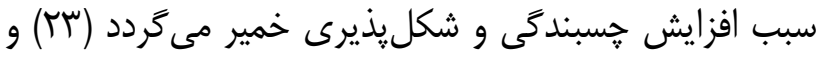

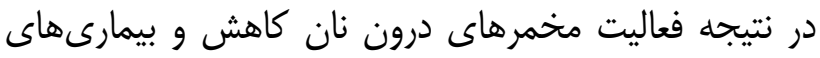

نتايج نشان مىدهد ميانگين ميزان نمك در انواع نانها

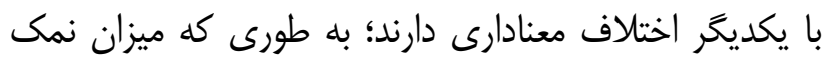
در نان لواش بيشتر از سنگك و تافتون، و در نان تافتون بيشتر از نان سنخگ است كه علت اين تفاوت را مئتوان كيفيت و قابليت جذب آب توسط آرد دانست؛ همجنين بر آنين اساس فرمولاسيون جديد تهيه نان، نمك بلصورت محلول به

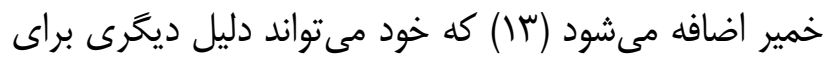
اين تفاوت باشد. در مطالعهاى كه بر روى نانهاى اصناى استان

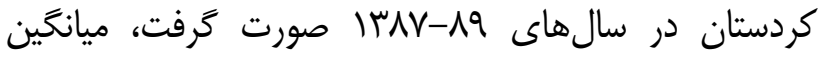

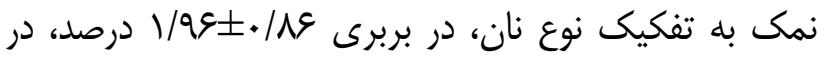

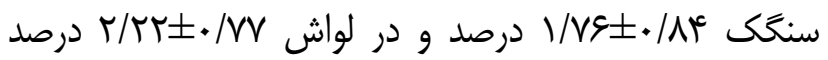
بود (•) كه نشان داد ميزان نمك در نان لواش بيشتر است. اين نتيجه با نتايج مطالعه حاضر همخوانى دارد. نئن

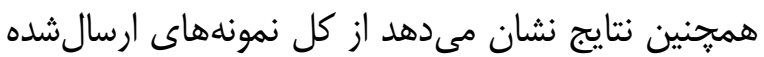

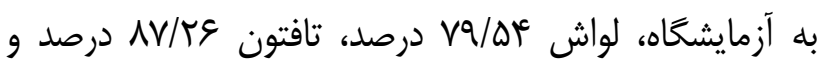

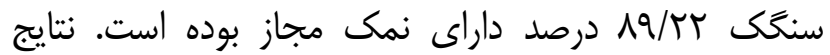

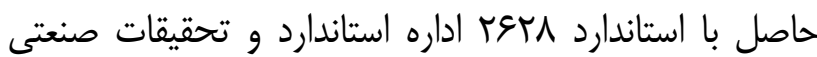

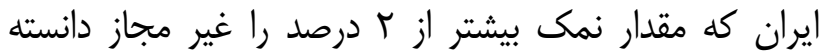

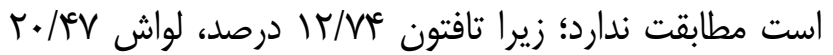

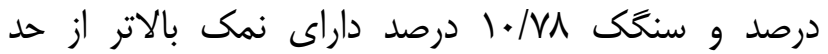
استاندارد بوده است. طبق بررسى انجامشده بر روى نانهاى دهاى دان

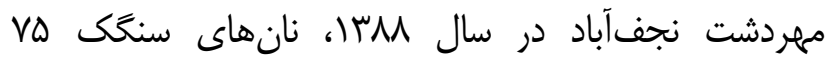

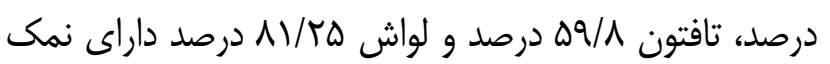

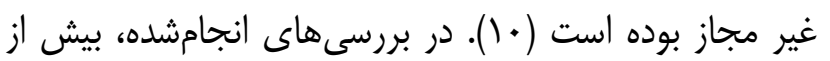

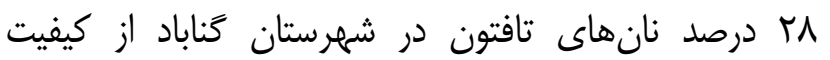

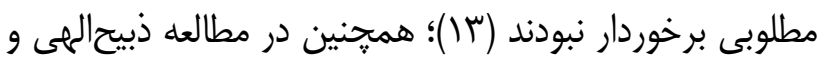

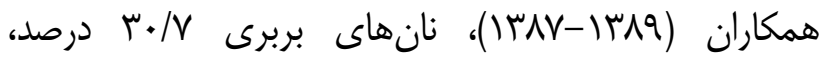

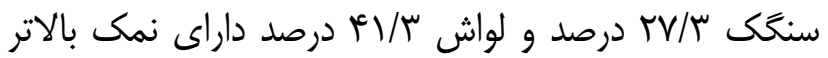
از حد مجاز بودند (1). در بررسى ميزان نمك نانها در

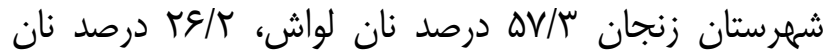
بربرى و 11/ درصد نانهاى ديخر داراى نمك غير استاندارد بودند (أl) كه با نتايج مطالعه حاضر همخوانى دارد. 
برخورد جدى بلمنظور دستيابى به هدف مدّ نظر، نقش مؤثّى

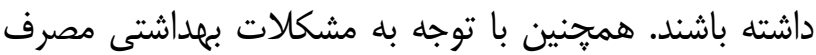
بيش از حد نمك، بايستى از نانهايى مانند سنگك استفاده

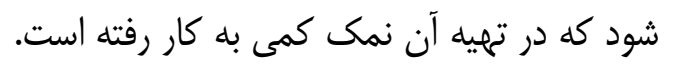

\section{نتيجه كيرى}

مقدار نمك مصرفى از نظر تغييرات ميانخين مصرف نان

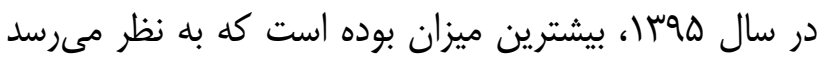

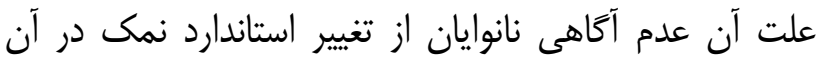

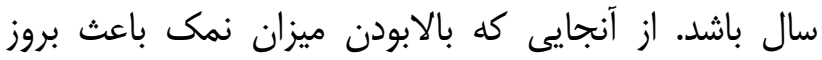
بيمارىهاى فشار خون، سكته مغزى و قلبى مى

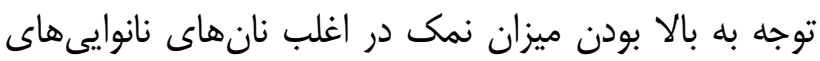

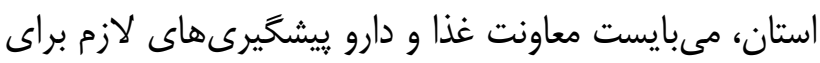
كاهش ميزان نمك در نانهاى عرضهشده به بازار را انجام

\section{تقدير و تشكر}

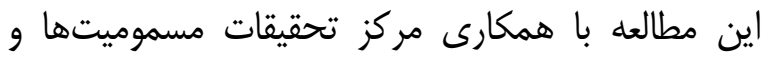

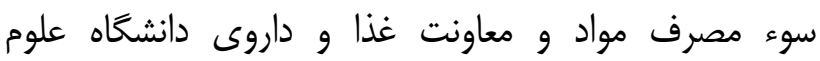

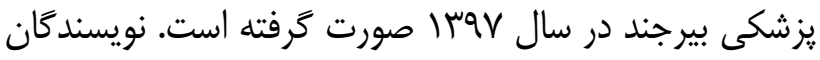

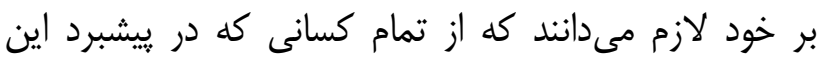
تحقيق همكارى كردند، تشكر نمايند.

تضاد منافع نويسندكان مقاله اعلام مى دارند كه هيج گَونه تضاد منافعى در يزوهش حاضر وجود ندارد.
قلبى و عروقى، فشار خون بالا و بيمارىهاى كليوى افزايش

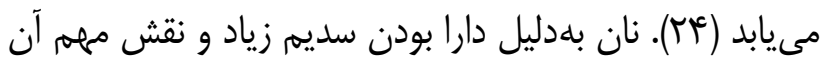

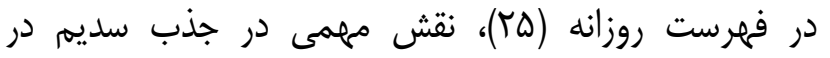

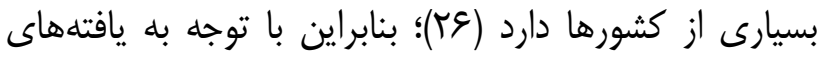
اين يثروهش، از آن جايى كه نان يك سوم كالرى مردم كشور

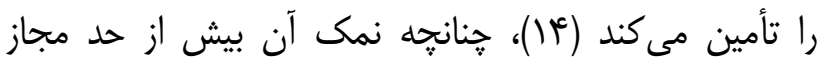
باشد بهعنوان يك تهديد سلامتى به خصوص در در افرادى كه بايد رزيم كم نمك داشته باشند، محسوب مى شع شود (19).

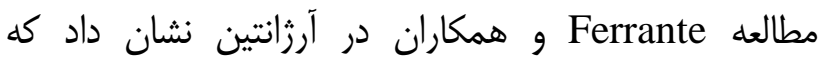
كاهش نمك رزيه غذايى در جمعيت مورد مطالعه با كاهش

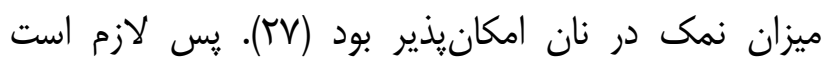
برنامههاى آموزشى و نظارتى مستمر و دقيقى براى ارتقاى

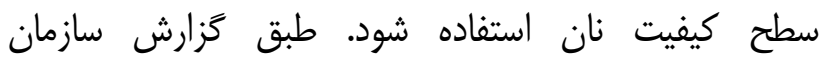

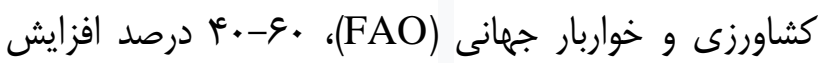
توليدات محصولات كشاورزى ناشى از كودهاى شيميايى

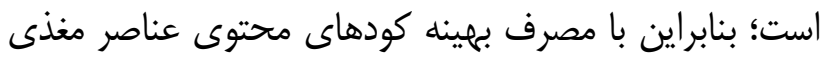

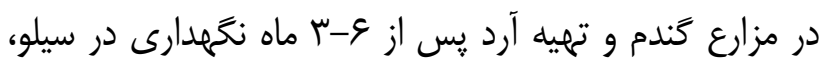

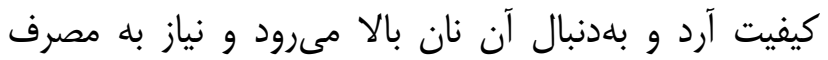

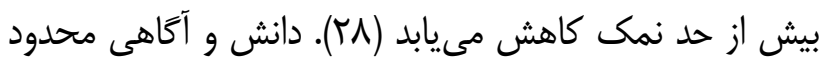
نانوايان و وقت گير بودن تهيه خمير ترش، سبب شده است

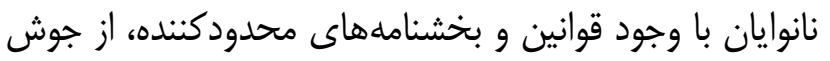

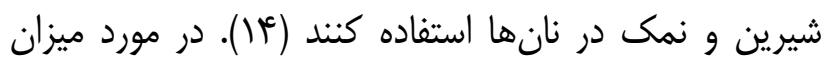

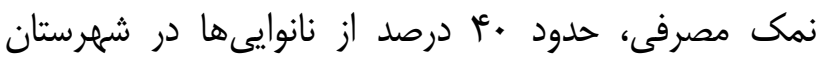

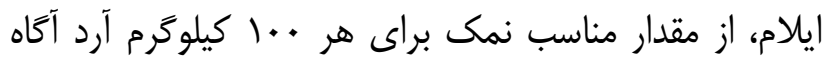

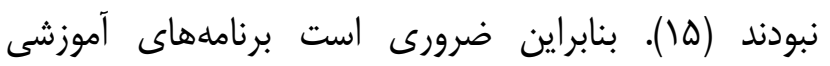
بلمنظور افزايش آكاهى در زمينه ابعاد علمى و استانداردهاى

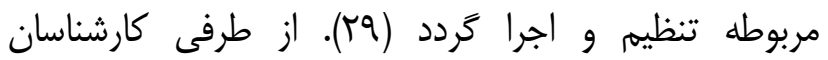
مهندسى بهداشت محيط مىتواند با بازرسى معمول خود و

1- Zabihollahi T, Goftari S, Garibi F, Naderi K, Korani A, Danesh O, et al. Investigation of the amount of sodium bicarbonate and salt in different types of bread in the bakeries of Kurdistan Province from 1387 to 1389 . Sci J Kurdistan Univ Med Sci. 2013; 18(3): 39-46. [Persian]

2- Robatgazi M, Khamirchi R, Rakhshani M. Study of bakers environment in Sabzevar. Journal of Medical Sciences and Research Committee of Sabzevar. 2006; 17(19): 17-9. [Persian] 
3- Quilez J, Salas-Salvado J. Salt in bread in Europe: potential benefits of reduction. Nutr Rev. 2012; 70(11): 666-78. doi: 10.1111/j.1753-4887.2012.00540.x.

4- Scientific Committee of the Food Safety Authority of Ireland. Salt and health: review of the scientific evidence and recommendations for public policy in Ireland (Revision 1). Dublin, Ireland: Food Safety Authority of Ireland; 2016

5- Meneton P, Jeunemaitre X, de Wardener HE, Macgregor GA. Links between dietary salt intake, renal salt handling, blood pressure, and cardiovascular diseases. Physiol Rev. 2005; 85(2): 679-715. doi: 10.1152/physrev.00056.2003

6- Brune M, Rossander-Hultén L, Hallberg L, Gleerup A, Sandberg AS. Iron absorption from bread in humans: inhibiting effects of cereal fiber, phytate and inositol phosphates with different numbers of phosphate groups. J Nutr. 1992; 122(3): 442-9. doi: 10.1093/jn/122.3.442

7- Naghibi SA, Yahyazadeh R, Yazdani Cherati J. Knowledge, attitude referred to health centers on salt intake. J Mazandaran Univ Med Sc. 2012; 22(95): 99-104. [Persian]

8- Azizi A, Amirian F, Amirian M. Effects of knowledge, attitude and practice of married women with community oriented medical education in City of Kermanshah City on Iodized Salt Consumption (2004). Iran J Endocrinol Metab. 2008; 10(3): 205-10. [Persian]

9- Ja'farpour M, Mahmoodian A, Ja'farpour S. Effects of high sodium chloride intake on big arterial wall. Kowsar Med J. 2011; 16(1): 33-7.

10- Rezaei-Mofrad MR, Rangraz-Jeddi F, Moosavi GhA. Amount of baking soda and salt in bakeries of Mehrdasht city (Najafabad) during 2009-10. Feyz, J Kashan Univ Med Sci. 2011; 15(3): 267-73. [Persian]

11- Irani P, Zargaran M. Determination of optimum Compositions of Flour and Dough for Production of Iranian Flat Bread. Journal of Agriculture Engineering Research. 2006; 6(25): 15-30. [Persian]

12- Iranian National Standards Organization (INSO). Traditional breads Specifications and test methods. Theran, Iran: INSO; 2016. National Standard No. 2628.

13- Alami A, Banoorkar S, Rostamiyan T, Asadzadeh SN, Mohammadzadeh Moghaddam M. Quality assessment of traditional breads in Gonabad bakeries, Iran. Journal of Research and Health. 2014; 4(3): 835-41.

14- Chamandoost S, Naderi M, Afshar H, Kamali K. Amount of baking soda and salt in bakeries of Zanjan city in 20112012. J Hum Environ Health Promot. 2015; 1(1): 56-62. [Persian] doi: 10.29252/jhehp.1.1.8

15- Gholami Parizad E, Khosravi A, Pourabas A, Mahdizadeh MA. A study on the effective factors of bread wastes in Ilam urban bakeries (2006-7). J Ilam Univ Medi Sci. 2009; 16(4): 8-17. [Persian]

16- Hashemi M, Afshari A, Aminzare M, Raeisi M, Sahranavard T. Evaluation of pH and Common Salt Content in Bread Samples Produced in Mashhad, Iran. J Food Qual Hazards Control. 2016; 3(2): 73-5. [Persian]

17- Hoseini A, Firozkohi M, Zoragi A, Hagani Far H, Bazrafshan E. Elimination of Soda in Systan va Balochestan Provence from 2004-2007. In: Proceedings of the $11^{\text {th }}$ National Congress of Environmental Health. COI Code: NCEH11; 2008 Oct 28-29; Zahedan, Iran. CIVILICA.

18- Ahangaran S, Hajipour Nejad A. Investigating the amount of bread salt and gluten flour in Shiraz bakery units summer 83. In: Abstracts 9th Iranian Nutrition Congress Tabriz; 2006 Sep 4-7; Tabriz University of Medical Sciences, Tabriz, Iran.

19- Malakoutian M, Loloei M. The quality and hygienic condition of Bread in Rafsanjan'S bakeries. J Rafsanjan Univ Medi Sci. 2003; 2(3-4): 180-6. [Persian]

20- Brinsden HC, He FJ, Jenner KH, MacGregor GA. Surveys of the salt content in UK bread: progress made and further reductions possible. BMJ open. 2013; 3(6): e002936. doi: 10.1136/bmjopen-2013-002936

21- Talaei M, Mohammadifard N, Khaje MR, Sarrafzadegan N, Sajjadi F, Alikhasi H, et al. Healthy bread initiative: methods, findings, and theories-Isfahan Healthy Heart Program. J Health Popul Nutr. 2013; 31(1): 49-57. doi: 10.3329/jhpn.v31i1.14748

22- Khamirchi R, Tavana E, Akaberi A. The levels of sodium bicarbonate and salt in different types of bread in Sabzevar bakeries in 2006-2007. J Sabzevar Univ Medi Sci. 2010; 17(2): 135-42. [Persian] 
23- Sheikh-ol-Eslami Z, Jamalian J. Investigation of Phytic Acid Contents of Wheat Flour, Dough and Lavash and Sangak Breads. JWSS. 2003; 7(2): 185-92. [Persian]

24- Takbiri MR. Dough-baked prerequisite of safe bread producing. Journal of Iran dough-baked. 2005; 6: 3-5. [Persian]

25- Brown IJ, Tzoulaki I, Candeias V, Elliott P. Salt intakes around the world: implications for public health. Int J Epidemiol. 2009; 38(3): 791-813. doi: 10.1093/ije/dyp139.

26- Bolhuis DP, Temme EH, Koeman FT, Noort MW, Kremer S, Janssen AM. A salt reduction of 50\% in bread does not decrease bread consumption or increase sodium intake by the choice of sandwich fillings. JN, The Journal of nutrition. 2011; 141(12): 2249-55. doi: 10.3945/jn.111.141366

27- Ferrante D, Apro N, Ferreira V, Virgolini M, Aguilar V, Sosa M, et al. Feasibility of salt reduction in processed foods in Argentina. Rev Panam Salud Publica. 2011; 29(2): 69-75. DOI: 10.1590/S1020-49892011000200001 .

28- Malakouti M. Towards improving the quality of consumed breads in Iran: A review. 2011: 8 (31): 11-21. [Persian]

29- Omidvar N, Aminpour A, Ghavamsadri M, Kavian F, Rokni S. Knowledge, Attitude, and Practice of Bakers Regarding Different Aspects of Bread Production in the City of Tehran. Iranian Journal of Nutrition Sciences \& Food Technology. 2007; 2(2): 27-36. [Persian] 